\title{
Caffeinilium Chlorochromate: As a Mild and Efficient Reagent for Oxidation of Alcohols and Chemoselective Oxidative Cleavage of Oximes
}

\author{
F. Shirini, I. Mohammadpoor-Baltork, ${ }^{\dagger}$ Z. Hejazi, and P. Heravi \\ Department of Chemistry, C'ollege of Science, Gulan Lhiversity, P.O. Box 1913, Rash H335, Iran \\ ${ }^{\dagger}$ Department of Chemisty. College of Science, Isfahan Lniversity, Isfahan, Iran \\ Received October 24, 2002
}

Key Words : Calleme, Calleinilium chlerewhromate, Oximes:

Oxidation of organic compounds under nonaqueous and aprotic conditions is an important reaction in synthetic organic chemistry. For this purpose different $\mathrm{Cr}$ (VI) based oxidants are reported in the literature. ${ }^{1-9}$ However, some of the reported reagents suffer from disadvantages such as instability: hygroscopicity: low selectivity, long reaction time difficulty of preparation and need for a large excess of the reagent. Thus a milder. more selective and inexpensive reagent is still in demand.

ln connection with our ongoing research program directed toward the development of new oxidizing agents and systems. ${ }^{\text {(i) }}$ we wish to report the oxidizing property of a new mild oxidizing agent. caffenilium chlorochromate (CCC). CCC was prepared by the addition of caffeine to a solution of an equimolar amount of $\mathrm{CrO}_{3}$ in $6 \mathrm{M} \mathrm{HCl}$ at $0{ }^{\circ} \mathrm{C}$ and obtained in $86 \%$ yield as an orange solid. CCC was stable when kept at room temperature for a long period of time. This oxidizing agent is soluble in hot water, acetone and acetonitrile and is insoluble in cold water, benzene and carbon tetracliloride. The structure of CCC was determined by elemental analysis and infrared spectral data.

Primary and secondary benzy lic and saturated alcohols are comverted to their corresponding carbomyl compounds in good to high yields (Table l. Entries l-11). Further oxidation of aldehydes to their carboxylic acids was not observed. Under the same conditions allylic alcohols are selectively oxidized to their corresponding $\alpha . \beta$-unsaturated carbonyl compounds without the cleavage of carbon-carbon double bonds (Table 1. Entry 12).

The oxidative cleavage of oximes to their corresponding carbonyl compounds were also performed by this reagent (Table 1. Entries 13-20). Hydrazones do not undergo oxidative cleavage with this method (Table 1. Entries 21 .
22). Therefore, this methodology shows selectivity and is suitable for oxidative selection between oximes and hydrazones. This is exemplified by the competitive reaction between 4-phenylacetophenone oxime and 4-methylbenzaldehyde phenylhydrazone (Scheme 1).

ln conclusion the mildness, stability: high efficiency. selectivity; reasonable yields of products simple and clean work-up and heterogeneous reaction conditions make this method a useful addition to the present methodologies for the oxidation of alcohols and chemoselective oxidative cleavage of oximes.

\section{Experimental Section}

Preparation of caffeinilium chlorochromate: To a solution of $\mathrm{CrO}_{3}(10 \mathrm{~g} .0 .1 \mathrm{mmol})$ in $6 \mathrm{M} \mathrm{HCl}(10 \mathrm{~mL})$ was slowly added caffeine (1.92 g. $0.1 \mathrm{mmnol}$ ) and the mixture was stirred at $0^{\circ} \mathrm{C}$ for $2 \mathrm{~h}$. The cold mixture was filtered on a sintered glass fumuel and the orange solids were collected. The product was dried in vacho at room temperature for 3 days to give $\mathrm{CCC}\left(\mathrm{mp}>240{ }^{\circ} \mathrm{C}\right.$ ) in $86 \%$ yield. ' $\mathrm{H}$ NMR $\left(\mathrm{CDCl}_{3}\right) \delta 2.70(\mathrm{~s}, 6 \mathrm{H}), 3.63(\mathrm{~s}, 3 \mathrm{H}), 9.5(\mathrm{~s}, \mathrm{lH}):$ IR $(\mathrm{KBr}$ pellet) $940,900,760 \mathrm{~cm}^{-1}$. Anal Calcd for $\mathrm{C}_{8} \mathrm{H}_{1} \mathrm{ClCrN}_{1} \mathrm{O}_{5}$ : C. 29.06: H. 3.35: N. 16.94. Found: C. 29.08: H. 3.45: N. 17.00 .

General procedure for oxidation of alcohols: To a solution of the substrate $(1 \mathrm{mmol})$ in $\mathrm{CH}_{2} \mathrm{Cl}_{2}(5 \mathrm{~mL})$ was added CCC (2 mumol) and the mixture was stirred magnetically under reflux condition for the specified period of time (Table 1). The progress of the reaction was monitored by TLC. After completion of the reaction. the mixture was filtered and the solid residue was washed with $\mathrm{CH}_{2} \mathrm{Cl}_{2}(20$ $\mathrm{mL})$. Evaporation of the solvent followed by columu

4-Phenylacetophenone oxime

4-Phenylacetophenone

$90 \%$

$$
\underset{\text { reflux, } 1 \mathrm{~h}}{\stackrel{\mathrm{CCC}, \mathrm{CH}_{2} \mathrm{Cl}}{\longrightarrow}}
$$

4-Methylbenzaldehyde phenylhydrazone

4-Methylbenzaldehyde

$0 \%$

Scheme 1

*Corresponding author. Fax: +98-1.31-3220066: F-mail: shirinía guilan.ac.ir 
Table 1. Oxidation of alcohols and oxidative cleavage of oximes with $\mathrm{CCC}^{\circ}$

\begin{tabular}{|c|c|c|c|c|}
\hline Entrỵ & Substrate & Product & Time (h) & Yicld ${ }^{\circ} 0^{6}$ \\
\hline 1 & Benzỵl alcohol & Benzaldehỵde & 0.75 & 95 \\
\hline 2 & 2-Bromobenzyl alcohol & 2-Bromobenzaldehyde & 0.5 & 90 \\
\hline 3 & 2-Chlorobenzyl alcohol & 2-Chlorobenzaldehyde & 2.5 & 87 \\
\hline 4 & 4-Chlorobenzyl alcohol & 4-Chlorobenzaldehỵde & 2 & 92 \\
\hline 5 & 3-Nitrobenzyl alcohol & 3-Nitrobelzaldehyde & 4 & 90 \\
\hline 6 & 1-Phenyl sthanol & Acetophenone & 0.75 & 85 \\
\hline 7 & Diphenylcarbinol & Benzophenone & 3 & 90 \\
\hline 8 & Cyclohexanol & Criclohexanone & 0.3 & 87 \\
\hline 9 & 3-Phemylpropanc-2-ol & 3-Phenỵlpropanal & 1.2 & 90 \\
\hline 10 & 1-Phemylpropance-2-ol & Phenvilpropanc-2-one & 1 & 85 \\
\hline 11 & Phenylethyleneglycol & Phemỵlglyoxal & 2.7 & 80 \\
\hline 12 & Cinnamyl alcohol & Cinnamaldehỵde & 0.8 & 80 \\
\hline 13 & 4-Chlorobenzaldehyde oxime & 4-Chlorobeizaldehyde & 0.75 & 90 \\
\hline 14 & 2-Methosịbenzaldehyide oxine & 2-Methoxybenzaldehyde & 0.3 & 92 \\
\hline 15 & 4-Phenylacetophenone oxime & 4-Phenlacetophenone & 0.83 & 87 \\
\hline 16 & 3-Acetylpyridine oxime & 3-Acetylpyridine & 2 & 85 \\
\hline 17 & 4-Acetylpy ridine oxime & 4-Acetylpyridine & 5.25 & 90 \\
\hline 18 & 1-Tetralone oxime & 1-Tetralone & 1.1 & 85 \\
\hline 19 & Champhor oxime & Champhor & 3 & 82 \\
\hline 20 & Cyclohexanone oxime & Cyelohesanonc & 1 & 85 \\
\hline 21 & 4-P'henylylace tophenone phens llyydrazone & 4-Phenylylacetophenone & 6 & 0 \\
\hline 22 & 4-Methylacetophenone phenyllyydrazone & 4-Methy lacetophenone & 3.5 & 0 \\
\hline
\end{tabular}

"All products were characterized by infiared (IR) and 'II NMR spectroscops' and by comparison with authentic samples. 'Tsolated sicld.

cluromatograply on silica gel gave the corresponding carbonyl compounds in good to high yields.

General procedure for oxidation of oximes: To a solution of the substrate ( $1 \mathrm{mmol})$ in $\mathrm{CH}_{2} \mathrm{Cl}_{2}(5 \mathrm{~mL})$, was added $C C C$ ( $2 \mathrm{mmol}$ ) and the mixture refluxed for the specified period of time (Table 1). The progress of the reaction was monitored by TLC. After completion of the reaction. the mixture was filtered and the solid material was washed with $\mathrm{CH}_{2} \mathrm{Cl}_{2}(20 \mathrm{~mL})$. The combined filtrates were evaporated on a rotary exaporator and the resulting crude material was purified on silica gel column. Exaporation of the solvent afforded pure carbonyl compounds in good to high yields.

Acknowledgment. We wish to thank Dr. R. Sariri for her help. Also, we are thankful to Guilan University Research Council for the partial support of this work.

\section{References}

1. Cainelli. G.: Cardillo. G. Chrmminn Oxidatoms in Onganic
Chemishy: Spritiger-Verlag: Berlin, 1984: Vol 19

2. I.uzzio, F. A.: Guzice, F. S. Ong. Prop. \& Irocedore Int 1988, 20. 5.3.

3. Firomzabadi. H.: Sharili. A. Sinthesis 1992.999.

4. Li. M.: Johnson. M. E. Sinth Commun, 1995. 25. 533.

5. Lee. J. G.: Lim. H. I.: Ha. D. S. Bull Korean Chem. Soc, 1987. S. 4.35

6. Salchi, P.: Khodaci, M. M.: Goodarzi. M. Symh. Commun 2002. 32. 1259

7. Khodaei. M. M.: Salehi. P'.: Groodarzi. M. Swath. Comman. 2001. 3l. 1253.

8. Zhang. G.-S.: Chai. B. Indian J. Chem. Sece. B; Org. Chem . Hed Chem. 2001. $t 0(12) .1264$

9. Tajbakhsh, M.: Ghacmi. M.: Sarabi, S.: Chlasemzadeh, M.: IIeravi. M. M. Honatshefe Fun Cheme 2000. 131. 121.3.

10. Shirini. F.: Tajik. H.: Jalili. F. Sinth. Commtan. 2001. $3 /$. $288 \overline{5}$.

11. Shirini. F.: Azadbar. M. R. Symh Common. 2001. 3/. 3775.

12. Shirini, F. 7oltigol. M. A.; Pourhabib. A. J. Chem. Res. (S) 2001. 476 .

1.3. Shirini, F.: 7oltigol. M. A.: Mallakpour. B.: Mallakpour, S. E.: Hajipour. A. R. instralin. . (he'm. 2001. 5f. 405.

14. Shirini. F.: Mamaghani. M.: Parsa. F.: Mohammadpour-Baltork. I. Bull. Korvan (he'm. Soc. 2002. 23. 1683. 